International Journal of Physical Distribution \& Logistics Management, Volume 43, Issue 9, 2013, Pages 747-767

This article is (c) Emerald Group Publishing and permission has been granted for this version to appear here (https://dspace.lib.cranfield.ac.uk/index.jsp). Emerald does not

grant permission for this article to be further copied/distributed or hosted elsewhere without the express permission from Emerald Group Publishing Limited.

www.emeraldinsight.com

\title{
Lateral transshipments: An institutional theory perspective.
}

\section{Abstract}

Purpose: Are lateral transshipments an effective instrument to ensure the safe and efficient supply of blood? This paper will use the lens of institutional theory to determine how the blood supply chain can benefit from lateral transshipments and what requirements are necessary for their implementation.

Design/methodology/approach: The research design comprises two stages. Firstly, 16 case studies clustered into 2 case groups were conducted with transfusion laboratories in UK hospitals resulting in the derivation of 8 key themes which were tested using a follow up survey.

Findings: The blood supply chain acts under the influence of significant institutional pressures. Coercive pressures result from regulations enforced to ensure the safe supply of blood, normative pressures are imposed by society, demanding wastage is minimized and mimetic pressure from other hospitals fosters efficient supply chain operation. Lateral transshipments offer a powerful organizational tool to allow the blood supply chain to conform to these pressures.

Research limitations/implications: This paper offers a novel institutional perspective on a complex supply chain issue where additional external pressures are seen to complicate the context. Due to the special characteristics of the blood supply chain, generalization of the findings to other industries must be done with care.

Practical implications (if applicable): The paper confirms the benefits of lateral transshipments in a perishable product context. Special requirements for the blood supply chain / health care services are identified.

Originality/value: The key contributions of this paper are five propositions which offer an institutional theory perspective on the application of lateral transshipment relationships in the blood supply chain.

Keywords: institutional theory, supply chain management, horizontal collaboration, case study, inventory pooling, stock sharing, blood 


\section{Introduction}

Traditional inventory systems are organized on a hierarchical basis with transportation flows from one echelon to the next (Waters, 2003). More flexible systems also allow lateral transshipments, an example of horizontal collaboration, where inventory is shared between organizations on the same level in the supply chain. Lateral transshipments support organizations in dealing with demand variability and stock outs (Evers, 1997) and can lead to a more balanced inventory system (Diks and de Kok, 1996). In a recent review of the use of lateral transshipments in inventory management, 94 models were reviewed and classified (Paterson et al., 2011).

Blood is a perishable product; stock control is therefore a trade-off between shortage and wastage, with potentially fatal consequences should a stock out occur. Careful management of blood inventories is crucial, as availability and an efficient use of the scarce resource is essential in addition to inventory holding and stock out costs. With a declining donor base and increasing security and safety regulations (Reynolds et al., 2001) further research into the optimization of the blood supply chain is required (Rytilä and Spens, 2006). Lateral Transshipments are potentially a powerful tool in this context. As the review of Paterson et al. (2011) found no studies which dealt with blood specifically or perishable products in general this paper seeks to explore the application and benefits to the blood supply chain.

From an institutional theory perspective, organizations are social systems (Scott, 1987). This theoretical framework has been used to explain why organizations adopt policies, procedures and practices (Meyer and Rowan, 1977) and also explains what their response and actions to environmental pressures should be (Grewal and Dharwadkar, 2002). In this paper we use 16 case studies with hospitals in the United Kingdom (UK) blood supply chain and apply institutional theory to investigate how and why lateral transshipments are used in the blood supply chain.

The paper will give an overview of lateral transshipments, the blood supply chain and institutional theory followed by three research questions. The case study method is employed; cross-case-analysis leads to a discussion of the findings through the lens of institutional theory in the context of the research questions and their managerial and theoretical implications. 


\section{Literature Review}

\section{Lateral Transshipments}

Lateral transshipments are an example of horizontal collaboration. Supply chain collaboration in general is well researched and the benefits are evident; increased efficiency and flexibility, lower costs for distribution and logistics and reduced cycle times (Mena et al., 2009, Mentzer et al., 2000). In addition, Daugherty (2011) described relationships within supply chains as a fascinating and dynamic research area for the future.

Lateral transshipments are an important tool in supply chain management, as they can help reduce costs and/or increase service levels. However, there is currently no uniform terminology: Kendall and Lee (1980) refer to stock rotation, Ballou and Burnetas (2003) used the term cross-filling. Others often refer to lateral transshipments (Gao et al., 2011, Paterson et al., 2011) or inventory pooling (Kranenburg and van Houtum, 2009, Wong et al., 2007). The term "emergency lateral transshipments" is also used in this context (Evers, 1997). In this paper, we use the term "lateral transshipments" and refer to the sharing or rotating of stock on the same echelon in the supply chain on a horizontal level. The nature of a lateral transshipment arrangement can be categorized into two dimensions: intensity and timeframe (Paterson et al., 2011). Intensity is further subdivided into complete pooling or partial pooling and timeframe classified as either proactive or reactive. The timing for proactive transshipments is restricted to pre-defined times, whereas reactive transshipments can take place at any time. In this paper we focus on proactive transshipments to maximize availability whilst minimizing wastage, not to respond to urgent demand. Therefore, emergency situations where extraordinary transshipments are carried out are not in the scope of this paper.

Lateral transshipments are predominantly used in the airline and spare parts industries and retailing. The cost of availability of spare parts is a major success factor in maximizing aircraft utilization and lateral transshipments are a way of exploiting economies of scale in this environment (Kilpi and Vepsäläinen, 2004). The airline industry represents only a small proportion of the spare and service parts industry, where horizontal collaboration and inventory pooling is widely implemented (Satir et al., 2012, Kranenburg and van Houtum, 2009, Wong et al., 2007) .

The blood supply chain

Blood appears to be available for all, however blood components remain a limited and precious resource (Reynolds et al., 2001) as they cannot be manufactured artificially and supply depends on 
human donors. As blood is a perishable product, hospital inventory decisions constantly trade off shortages against wastage, to provide the highest availability and service levels for patients at the lowest wastage rates (Pierskalla, 2005). Wasting a unit of blood is not only a financial loss for the hospital, but also the loss of a freely donated resource. This makes the blood supply chain special and different from commercial supply chains. Classic inventory models using stock-out costs or costs for lost sales cannot be applied in health services, as a stock out can potentially lead to the death of a patient, this cannot be quantified in monetary terms (Pierskalla, 2005). Health services in general focus on patients and availability of products rather than following purely economic objectives (de Vries, 2011). The blood supply chain has been described elsewhere and the reader is directed to Stanger et al. (2012) andKatsaliaki (2008) for further details.

\section{Lateral Transshipments in the Blood Supply Chain}

The idea of collaboration in the blood supply chain is not new; as far back as 1980 Kendall and Lee discussed the concept of rotation and sharing of stock in this context. They developed blood rotation policies using a goal programming model for systematic redistribution of blood between hospitals with the aim of minimizing outdates and shortages. This is the only paper published on lateral transshipments specifically in the blood supply chain and as a mathematical modeling paper lacks any discussion of the contextual and organizational factors and requirements which facilitate and enable lateral transshipments in practice.

Sharing inventories leads to cost reductions, improved economic and service performance and allows smaller organizations to gain access to services which would not be available without cooperation (Schulz and Blecken, 2010). In the blood supply chain, sharing inventories has the potential to reduce overall inventories whilst keeping service levels high. Smaller hospitals could hold rarely required blood groups in their stocks and transfer the units to a bigger hospital when there is a risk of expiry. However, there are also barriers for example, Paterson et al. (2011) claim that the added flexibility also adds more complexity and requires good management and control.

The most important requirement identified is mutual trust to prevent opportunistic behavior (Schulz and Blecken, 2010). In addition, Cruijssen et al. (2007) found that the achieved benefits are very difficult to estimate in advance and a fair and equal sharing of these benefits is critical. In the blood supply chain these issues are particularly relevant when transshipping blood between private and state run hospitals. These hospitals compete in the market and therefore trust and equal sharing of benefits are significant. 
The wider literature also provides drivers and requirements to make lateral transshipments work in practice. Common IT systems enable communication and transparency as well as a streamlined logistics system for physical transfer, in addition the parties should be of roughly equal size in order to achieve equal benefits (Kilpi and Vepsäläinen, 2004). The literature therefore suggests that hospitals of roughly equal size, which do not compete in the same market, are most likely to benefit from a lateral transshipment relationship.

\section{Institutional theory}

To ensure a rigorous study a solid theoretical framework is required; in this case institutional theory was selected. Institutional theory focuses on how external pressures influence organizations and their organizational practice. As lateral transshipments require interactions outside the focus organization, institutional theory provides a solid framework to explain these pressures.

This section will briefly introduce institutional theory. It is not intended to provide a comprehensive review as there are various good reviews published, see: Williams et al. (2009), Sarkis et al. (2011) and Tate et al. (2011). Institutional theory provides a rich and complex view of organizational behavior (Meyer and Rowan, 1977). Scott (1995) defines institutions as "social structures that have attained a high degree of resilience ...[they] are composed of cultural-cognitive, normative and regulative elements that together with associated activities and resources, provide stability and meaning to social life". External institutional pressure is discussed widely in the literature divided into three isomorphic drivers/pressures/dimensions: coercive, normative and mimetic, these are summarized in table 1.

\begin{tabular}{|c|c|c|c|}
\hline & $\begin{array}{l}\text { Coercive } \\
\text { (Sarkis et al., 2011, Rivera, } \\
2004 \text { ) }\end{array}$ & $\begin{array}{l}\text { Normative } \\
\text { (Williams et al., 2009, Scott, } \\
\text { 1995, DiMaggio and Powell, } \\
\text { 1983) }\end{array}$ & $\begin{array}{l}\text { Mimetic } \\
\text { (Aerts et al., 2006, } \\
\text { DiMaggio and Powell, } \\
\text { 1983) }\end{array}$ \\
\hline Basis & $\begin{array}{l}\text { Political influence and } \\
\text { organizational legitimacy }\end{array}$ & Ethical and moral obligation & $\begin{array}{l}\text { Desire to look or behave } \\
\text { like others }\end{array}$ \\
\hline Form & $\begin{array}{l}\text { Laws } \\
\text { Governmental regulations }\end{array}$ & $\begin{array}{l}\text { Cultural expectations, } \\
\text { standards and norms }\end{array}$ & Copy behavior of others \\
\hline Actors & $\begin{array}{l}\text { Parties with power } \\
\text { Government } \\
\text { Suppliers/Customers }\end{array}$ & $\begin{array}{l}\text { Educational organizations } \\
\text { Trade associations } \\
\text { Industry groups } \\
\text { Interest groups } \\
\text { Public opinion } \\
\text { Customers }\end{array}$ & $\begin{array}{l}\text { Organizations in the } \\
\text { external environment } \\
\text { which appear similar and } \\
\text { successful }\end{array}$ \\
\hline
\end{tabular}




\begin{tabular}{|l|l|l|l|}
\hline Consequences & $\begin{array}{l}\text { Fines/fees } \\
\text { Trade barriers }\end{array}$ & Loss of esteem or image & \\
\hline
\end{tabular}

Table 1: Isomorphic Pressures of Institutional Theory

\section{Lateral transshipments in the blood supply chain - an institutional perspective}

In order to understand how lateral transshipments in the blood supply chain can be seen from an institutional perspective, the three isomorphic drivers are discussed in this context. Governmental regulations form the key driver in ensuring the safety of blood and represent the main coercive pressure in this environment. In a recent study Shi et al. (2012) highlight that this is also the case for green supply chain management. These take the form of regulations regarding handling, storage and transportation of blood components defined by the Medicines and Healthcare products Regulatory Agency (MHRA) in the UK (Taylor, 2001). Failure to supply safe blood could lead to the death of a patient, so the consequences both in terms of reputation and costs of not complying are severe. In addition medical staff within a hospital will have their own requirements regarding handling and availability.

The moral and ethical imperative is strong in the blood supply chain, leading to significant normative pressures. In the UK the donation of blood is unpaid and the supply of blood is entirely dependent on voluntary donations (Rock et al., 2000). Therefore, there is a moral duty towards the donors to ensure an efficient and appropriate use of blood. In addition there is also a moral duty towards the patients, as once wasted a unit cannot be used for another patient (Reynolds et al., 2001). In addition there is also a normative pressure from society to keep costs low, as the health system in the UK is funded by the government and hence by society. This means that blood units must not only be used in the most appropriate way but also the most cost-efficient way.

Mimetic pressures are driven by other hospitals. The National Health Service (NHS) fosters collaboration and knowledge exchange between hospitals, encouraging and facilitating individual hospitals to model their behaviors on those of hospitals which have been proven to have the most efficient procedures and policies. This knowledge exchange is fostered by regular local meetings of transfusion committees and data exchange (BSMS, 2011). As the hospital landscape in the UK is split into two major parts (private and state hospitals) mimetic pressures arise from both competitor and non-competitor hospitals. 
The overriding source of institutional pressure in this environment is therefore the efficient (i.e. reducing wastage) and safe delivery of blood; lateral transshipments provide an effective instrument to achieve this. Based on this brief discussion we adapt the framework of Williams et al. (2009) to our research questions and use this as a reference model for the empirical study, as shown in figure 1.

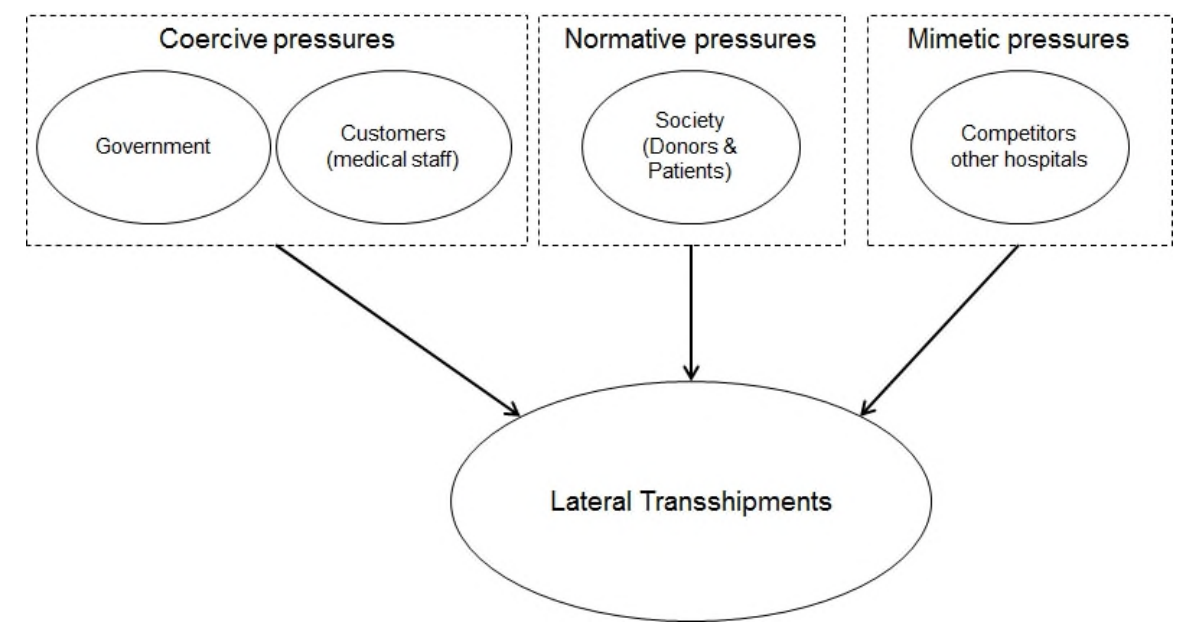

Figure 1: Research framework (adapted from Williams et al. (2009))

We have introduced institutional theory as the theoretical framework for our research, identifying potential sources of the three isomorphic external pressures of the theory. In the context of the blood supply chain the institution is identified as the efficient and safe delivery of blood. In this environment decisions based on purely monetary criteria are not acceptable, due to the predominance of service levels (Pierskalla, 2005) and the significant regulatory, moral and ethical imperatives which apply. This leads to our first research question:

RQ1: How does external pressure positively influence behavior in the blood supply chain to increase safety and efficiency?

The literature review discussed the various benefits of lateral transshipments and how they may be applied as an effective instrument in ensuring the safe and efficient operation of the blood supply chain. The overall aim of this research is to identify how lateral transshipment processes are structured, why they are adopted and to understand more fully how and why the identified external pressures influence this. This leads to our second research question:

RQ2: How is the lateral transshipment process, structure and organization influenced by external pressure?

However, we know that lateral transshipments are not utilized by all hospitals. If lateral transshipments are such a useful instrument for ensuring compliance with the institution of a safe and 
efficient supply of blood, why are they not universally adopted? This then leads to our final research question:

RQ3: Why does external pressure influence some hospitals to implement lateral transshipments and not others?

\section{Methodology}

In order to answer the research questions we employ the case study research method and apply institutional theory as a theoretical framework.

\section{The case study research method}

As only one paper is published on stock sharing in the blood supply chain context (Kendall and Lee, 1980 ) and no research into its practical application is published at all, this research is of an exploratory nature and the case study research method is appropriate. The case study methodology is suitable for exploration of complex processes (Eisenhardt, 1989) such as lateral transshipments and inventory processes in a niche sector like the blood supply chain. According to Yin (2009) the case study methodology allows for the retention of meaningful characteristics of real-life events such as managerial and organizational processes and therefore allows the inclusion of contextual factors and the institutional perspective into the research design. Schulz and Blecken (2010) and de Vries (2011) have both successfully employed the case study method in other specialist applications of inventory management and collaboration (disaster relief and healthcare services).

In order to answer RQ1 - RQ3 and understand lateral transhipments processes in detail, hospitals in the United Kingdom were selected as the unit of analysis. The hospitals were chosen based on an analysis of supply chain data contained in the database held by the Blood Stocks Management Scheme (BSMS). The BSMS was set up in the early 2000's in order to improve blood stocks management, a major benefit has been the establishment of this large database which collects data and information relating to blood stocks and wastage in hospitals and blood centres across the NHS. The availability of this data has already led to greatly improved transparency and consequently an increased understanding of blood inventory management (Chapman and Cook, 2002). In addition, results and raw data from a previous NHS blood inventory practice survey (Perera et al., 2009) were used to enrich the information from the BSMS database. Eisenhardt (1989) suggests limiting the number of cases to a maximum of seven, whereas Yin (2009) does not provide a rigid number of cases, but suggests collecting data until saturation. The research team concluded that this study 
required a comparison of hospitals involved in lateral transhipments, with those not currently involved. Therefore, 16 hospitals were selected clustered into two case groups, each containing sufficient participants to ensure a rigorous study, as shown in table 2. It was ensured that the selected hospitals were of different sizes and represented a wide geographic mix, as hospital size influences performance (Watcharasriroj and Tang, 2004) and to prevent biased information due to geographic specialties or anomalies.

Case Selection

\begin{tabular}{|l|l|}
\hline Case Group 1 & Case Group 2 \\
\hline 8 hospitals & 8 hospitals \\
\hline Actively sharing stock & Not sharing stock \\
\hline 3 University Hospitals & 2 University Hospitals \\
\hline 1 Large Hospital & 4 General District Hospital \\
\hline 4 General District Hospital & 2 Small Hospitals \\
\hline
\end{tabular}

Table 2: Characteristics of case groups used for the analysis

\section{Data Collection}

A two phase approach was taken to collect the data for this study. First a detailed and wide ranging interview was carried out in all 16 of the selected hospitals, to allow each participant to explore the area fully and ensure a full set of data was collected. Based on the analysis of these case studies a short survey was developed which was sent back to all 16 participants to confirm the findings.

Each case study was developed based on a detailed semi structured interview with the senior person responsible for blood inventory management in each of the 16 selected hospitals. This was usually the transfusion laboratory manager, who is in charge of all of the processes related to the inventory management of blood and as such has the most comprehensive overview of the operation in each hospital. A potential weakness of this approach is that each of the case studies is based on a single interview, which could potentially cause inconsistencies when comparing the results for each of the hospitals. However, the number of case studies carried out and the fact that these studies were divided into two groups meant that sufficient data was collected to meet the quality criteria of construct validity to avoid subjective judgments (Yin, 2009). In addition as the most senior person in each of the laboratories was interviewed, it is unlikely that another participant with enough knowledge and awareness of the operation would be available. 
Semi-structured interviews were carried out, as they allow in depth analysis of this complex and widely varying exploratory research area. They also allowing flexibility regarding the direction of the questions and do not neglect or miss important areas by restricting or predefining possible answers (Thietart, 2001). The interview guideline was designed based on findings from the literature, insights from the BSMS database, raw data from a previous inventory practice survey (Perera et al., 2009) and discussions with NHS Blood and Transplant (NHSBT) and BSMS staff. The interview guidelines were tested with NHSBT staff in advance to ensure that relevant terminology was applied correctly. Sixteen formal interviews took place between October and December 2010. The interviewees were provided with a compact version of the interview protocol beforehand (see appendix 1 for detailed questions) to allow them to prepare for the interviews.

\section{Case coding and analysis}

The interviews were transcribed and summarized and summaries sent back to the interviewees for their final approval. Miles and Huberman (1984) recommend a two stage analysis be conducted. Firstly, within-case analyses were conducted, where the collected data, for each case was analyzed individually, to summarize each case and identify the key characteristics and findings. The analysis identified eight categories based on themes and commonalities identified from the interviews and supported by the literature.

This was followed by a cross-case analysis to identify commonalities and differences across the hospitals, especially between the two case groups. During cross case analysis, the themes were compared across the two groups, ensuring that no categories were left out of the analysis and that all facets were incorporated, this allowed further data reduction and the derivation of valid propositions (Yin, 2009). Saturation was achieved after analysis of the $6^{\text {th }}$ interview for both case groups, the final two cases in each group revealing no additional themes; this indicated that the case groups were large enough to ensure consistency.

Due to the broad and complex nature of this research area and the fact that this is exploratory research, coupled with the possible deficiency in the data due to the single interviewee for each case a third step involving a questionnaire was used to confirm and validate the findings and ensure the sufficiency of the data. Based on the analysis, the key findings were summarized into eight statements, which were then sent back to the interviewees. The interviewees were asked to rate these statements on a five point Likert scale. All 16 interviewees rated the statements allowing the research team to verify the findings gained through within- and cross case data analysis and data reduction. 


\section{Results}

Within case analysis

All interviews for each of the two case groups were analyzed. A detailed description and display of the results from the within case analysis of all 16 cases was impractical due to the large amount of data involved.

\section{Cross case analysis}

In the cross-case analysis the results for the two case groups were compared. In case group 1 all hospitals are involved in lateral transshipments of blood. Four hospitals share stocks with multiple hospitals, whereas the remaining four only share with one partner. Case group 2 hospitals are not involved in active transshipment relationships.

In both case groups it was stated that lateral transshipments increase flexibility in inventory management, leading to reduced wastage levels due to a more efficient allocation of blood units. If a hospital has the ability to transfer units which are close to expiry to another hospital this creates the potential to prevent wastage due to time expiry. All the respondents agreed that reducing time expired wastage was a major benefit of lateral transshipment relationships. For example, one hospital has a lateral transshipment agreement with a smaller local hospital. The large hospital agreed to take all units with 5 days or less of remaining shelf life as they have sufficient patients of all blood groups to transfuse the units. Since setting up this relationship, the wastage rate of the small hospital has dropped significantly and the units wasted due to time expiry are now zero. The increased flexibility afforded by the ability to transfer stocks to another hospital allowed case group one hospitals to stock minor blood groups with less frequent demand in their regular stocks, these units had previously been ordered on an ad-hoc basis for individual patients. This not only increases availability, but also reduces the number of deliveries and hence transport costs and environmental impact. Five out of eight interviewees from case group 2 however, point out that transshipments could lead to higher wastage levels in the receiving hospital, as if a suitable patient for the transshipped blood unit cannot be found the unit will still be wasted. This increased risk requires some form of compensation mechanism for the receiving hospital. Case group 1 hospitals have developed various mechanisms for handling this risk and sharing the gained benefits.

All interviewees from both case groups agreed that cold chain validation is both the critical requirement and the key inhibitor for lateral transshipments. No hospital would transfuse blood units 
which do not meet the regulatory requirements due to the potential risk to patients' safety. The UK government regulations state that blood must be stored at between 2 and $6^{\circ} \mathrm{C}$ and any exposure to ambient temperature is restricted to 30 minutes. This requirement is strictly regulated and therefore good management of the cold chain together with a fully transparent audit trail is an essential requirement for sharing stock. All group 1 hospitals use validated transport boxes with special seals to ensure cold chain validity. The hospitals from case group 2 stressed that meeting the regulatory requirements for cold chain validation during transshipments is too challenging and the expected volumes are too small to justify such an effort. These validated boxes are expensive to buy and have to be audited on a regular basis, incurring an ongoing cost.

In order to guarantee a fully visible and safe cold chain, trust between the hospitals is essential, both as a key requirement and a success factor. This was stressed by all interviewees from both case groups, but particularly those actively involved in lateral transshipment agreements. Trust between the hospitals is critical, as flaws in processes and quality problems could potentially jeopardize patient safety. Hospitals are unable to transfuse blood units, where they are not $100 \%$ confident, that the unit was stored and handled in the required conditions. This trust is often based upon and dependent on long term personal contacts between transfusion managers. One hospital which has lateral transshipment agreements with three other hospitals has set up its own audit process, including regular unannounced audits where fridges are checked, processes are audited and the documentation is inspected. This process requires a huge amount of effort, however, the transfusion laboratory manager stressed that whilst trust is essential, scrutiny and monitoring of the processes is critical. This trust is especially important in relationships which go beyond legal entities.

In 7 hospitals from group 1 the handling of blood units especially with regard to the cold chain is formalized and documented in Standard Operating Procedures (SOP) and in Service Level Agreements (SLA) which formalize the transshipment agreement. The SLA also clearly states who has responsibility for cold chain validation and the exact point in the process when the responsibility is transferred to the other hospital, setting guidelines for the documentation of the process.

In order to facilitate transshipments between hospitals all interviewees from both groups stressed the necessity of SLAs and SOPs. The case group 2 interviewees however consider that the setting up of SOPs and SLAs is too time consuming and cannot be economically justified. When hospitals belong to the same legal entity, invoicing for transferred blood is not generally required as the hospitals operate a single budget. Hospitals who share units with different legal entities however either use monthly 
invoices, or they exchange units like with like and hence omit costly administrative overhead costs such as invoicing. Some hospitals invoice the transferred units at a discounted price in order to create an incentive for the other hospital to accept a unit which is close to expiry and take the increased risk of wastage. This is seen as a compensation for the increased risk of expiry and leads to a win-win situation for both hospitals as one hospital avoids wasting a unit due to time expiry whilst recovering some residual value whereas the other hospital can use the blood unit for a reduced rate.

Another theme derived from the data is the physical transfer of the blood units. When entering a lateral transshipment relationship, the blood units need to be transferred from one hospital to another. The hospitals which are not involved in lateral transshipments see this physical transfer as problematic due to the cold chain issues discussed above and the costs involved in using suitable transport. The hospitals involved in lateral transshipments either use special courier services or utilize regular transport which already exists between the hospitals. If a hospital can access this transport no additional costs for the transfer are incurred. For one hospital the distance to the next hospital is only a few meters and a member of staff can walk to deliver the blood.

\section{Survey Results}

The cross case analysis revealed a number of common themes which were discussed independently by several of the respondents. These were developed into eight common statements, shown in table 3 , which formed the basis of a survey sent back to the interviewees; the results are summarized in figure 2 according to a 5 point Likert scale.

\begin{tabular}{|c|c|c|}
\hline \multicolumn{2}{|c|}{ Statement } \\
\hline 1 & The cold chain validation is a major inhibitor / barrier for sharing stock with another hospital. \\
\hline 2 & The effort for setting up SLAs, SOPs and training staff outweighs the financial benefits gained \\
\hline 3 & Setting up a stock sharing relationship is time consuming and complex due to regulatory issues \\
\hline 4 & Transportation of units is a major problem for sharing stock with another hospital \\
\hline 5 & Stock sharing allows a more flexible management of blood stocks. \\
\hline 6 & Stock sharing enables stocking rare types of blood/components. \\
\hline 7 & The reduction of time expired wastage is a major benefit of sharing stock. \\
\hline
\end{tabular}




\begin{tabular}{|l|l|}
\hline 8 & Trust between the hospitals sharing blood is essential. \\
\hline
\end{tabular}

Table 3: Statements derived from cross- and within-case analysis

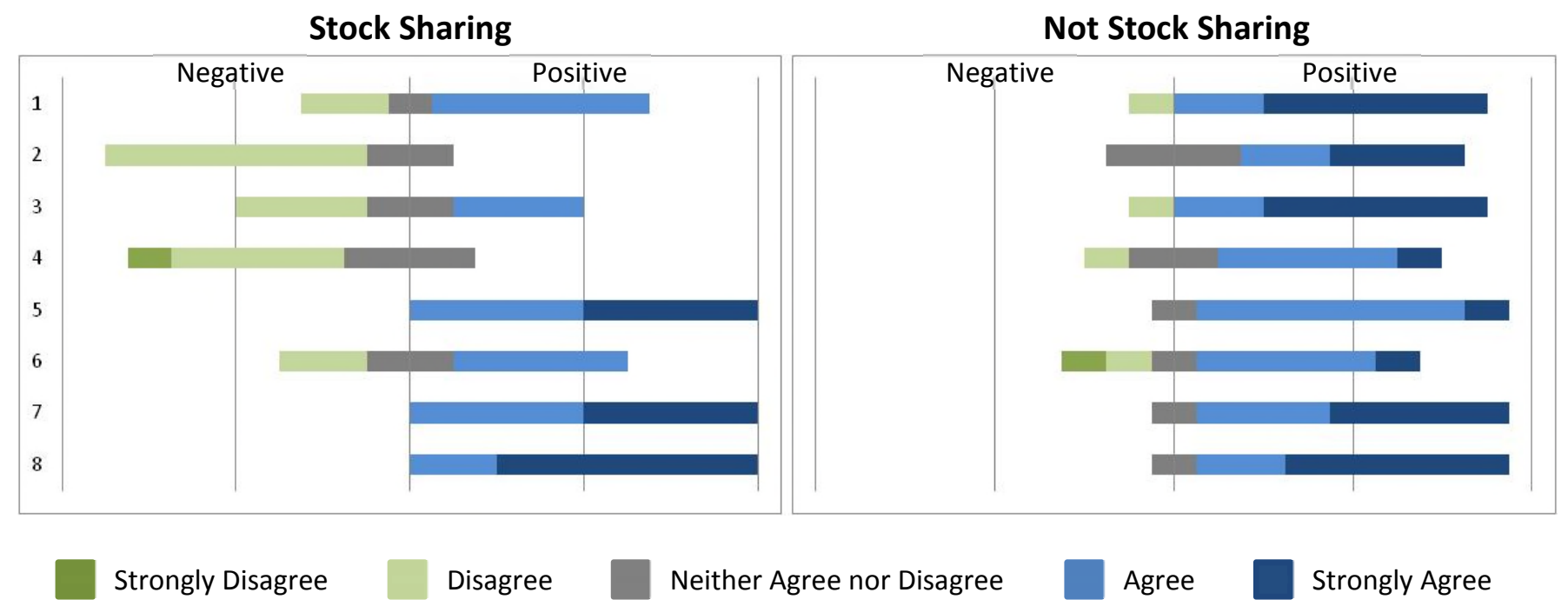

Figure 2: Summary of interviewees' responses to the survey questions

Figure 2 shows that the results for questions 1, 5, 6, 7 and 8 are effectively the same for the two case groups. Stock sharing allows flexibility in the management of blood stocks, reduces wastage due to time expiry and allows hospitals to stock rare blood components, cold chain validation is a major barrier to the implementation of a lateral transhipment arrangements and that trust is essential. However, there is a clear difference in the responses of the two groups to questions 2, 3 and 4 which relate to the mechanics of the processes, structure and organisation of a lateral transhipment relationship. Whilst those not currently involved in a stock sharing arrangement see that the effort of setting up processes (SLAs, SOPs and transport) and developing the required relationships to make this possible outweighs the potential benefits of such an arrangement, those who are currently involved in such a relationship do not see this to be so. The reasons for this difference will be discussed in the next section.

\section{Discussion}

This paper has investigated the practical application of lateral transshipments in the blood supply chain context. Up to this point the results have been presented thematically, in order to fully analyze the findings and extract all the possible commonalities and differences in the experience of the case study hospitals. Our focus will now shift to look at how external pressure impacts the ability of lateral 
transshipments to help the blood supply chain to efficiently supply safe blood. We will use the lens of institutional theory to interpret the findings to answer the research questions directly.

\section{RQ1: How does external pressure positively influence behavior in the blood supply chain to increase safety and efficiency?}

The key challenge in blood supply chain management is to provide the highest availability whilst minimizing wastage. Blood inventory management operates under a strong moral and ethical imperative to use the resource efficiently; this represents a significant normative pressure. In the UK blood is freely donated and hence the wastage of a unit is not only a wastage of money but also of the time and effort of the donor (Rock et al., 2000). This normative pressure from society (Selznick, 1957), especially from the patients and donors, is a key driver for transfusion laboratories to endeavor to minimize wastage and guarantee the most appropriate use of blood. In addition as blood must be transfused into a patient it is vital that the quality is maintained, therefore there is a normative pressure from society based on moral and ethical concerns (Scott, 1995) to ensure that blood components do not kill patients. This leads to our first proposition:

P1: The institution of the safe and efficient supply of blood is driven by a combination of normative pressures, based on the moral and ethical imperatives to use the resource efficiently and not to harm patients.

This research shows that lateral transshipments can support hospitals to increase efficiency by reducing wastage; transferring blood units to another hospital where a patient can be found. All hospitals in case group one (stock sharing) reported a reduction in wastage due to time expiry and all those in group 2 (not stock sharing) would expect a reduction in wastage under lateral transshipments. However, when transferring units to another hospital further costs for transport and administration occur as well as an increased risk of expiry in the receiving hospital. The benefits of reduced time expiry and a more balanced inventory system with increased flexibility have to be shared and accounted against the cost and risks that arise from lateral transshipment operations, this is difficult to do as has been discussed previously by Cruijssen et al. (2007). In some cases the achieved economic benefits of lateral transshipments are outweighed by the effort required to transfer blood units to another hospital. However, these relationships may be maintained as institutional pressures influence the operation in such a way that it is better not to waste a unit by time expiry even though it is not strictly economic to do so. 
A major driver for the majority of blood stocks managers was that good blood stocks management leads to efficient use of blood, which reduces wastage, leading to a reduction in the overall demand. The resultant overall economic and service performance is then substantially better, in agreement with the previous work of Tagaras (1999). In addition the desire to further reduce wastage has led the National Health Service Blood and Transplant (NHSBT), in the UK, to foster mimetic pressure between hospitals by encouraging them to exchange good practice through regular meetings and data sharing. This encouragement to imitate the paths to success of similar institutions is a direct embodiment of theoretical mimetic pressure as discussed by Aerts et al. (2006). This exchange also fosters collaboration between the hospitals on a personal level. Managers can learn from other hospitals, whilst in the same instance building relationships improving mutual trust. The research showed that trust between the hospitals exchanging blood is essential in order to guarantee product quality.

In summary we define the following propositions:

P2: The normative pressure of the desire to reduce wastage is a key driver in the development of lateral transshipment relationships.

P3: The mimetic pressure to share good practice leads directly to efficiency improvements in the blood supply chain.

In addition this mimetic pressure has the further benefit of driving the development of long term sustainable relationships between blood stock managers.

RQ2: How is the lateral transshipment process, structure and organization influenced by external pressure?

The study identified two major coercive external pressures which directly affect the implementation of lateral transshipments in the blood supply chain. The most significant is the effect of the Medicines and Healthcare products Regulatory Agency (MHRA) regulation on cold chain validation; this is a classic example of a coercive pressure exerted by government regulation in agreement with the theory (Sarkis et al., 2011). Cold chain validation was identified by the majority of the participants in the study from both case groups as the major barrier to setting up a successful lateral transshipment relationship. This shapes the way in which lateral transshipment relationships are established and maintained. The quality of blood must be maintained throughout the blood supply chain to ensure its safety, to protect the patient from ill effects or even death. The processes in place, including any actions taken during transshipment of a unit of blood, must not impede this quality; as such the 
government through the MHRA has put in place a set of regulations which must be adhered to throughout the blood supply chain. These regulations are strictly enforced and the consequences both in terms of reputation and cost are severe. Cold chain validation is therefore a critical issue derived from coercive pressures of governmental regulations.

In order to comply with this regulation this study identified that in all cases where stock sharing is currently taking place processes, such as Standard Operating Procedures (SOP) and Service Level Agreements (SLA), are in place to ensure cold chain validation is maintained. The imperative to develop these required organizational structures acts as a barrier to the adoption of lateral transshipment processes, in agreement with the previous findings of Schulz and Blecken (2010). The quantitative survey results elucidate this as one of the key differences between the two groups, whilst group one hospitals who are involved in such relationships think this effort is worthwhile; those in group two generally do not. In addition, all of the participants in the study agreed that a high level of trust is required to ensure that these processes are not only set up but that all participants in the supply chain have confidence that they are being adhered to. This is in line with the findings of previous studies looking at more general applications of lateral transshipments (Kilpi and Vepsäläinen, 2004).

The second major coercive external pressure identified was the pressure applied by customers, in line with the theory as described by Sarkis et al. (2011). In this case the customers are the hospital's medical and surgical departments. The most important factor for the medical and surgical staff is the availability of blood. This pressure often forces transfusion laboratory managers to hold excess stocks or to order these blood units on an ad-hoc basis, incurring an extra delivery cost. This coercive pressure to have the widest possible inventory of blood components available at all times is a major driver for setting up lateral transshipment relationships in the first place. A lateral transshipment relationship can essentially allow a group of hospitals to hold a common inventory, thus holding the widest range of blood components possible, whilst also reducing wastage and the costs of ad hoc deliveries. As such smaller organizations gain access to services not available to them without cooperation, in agreement with the previous findings of Schulz and Blecken (2010). In addition the collaboration afforded by the involvement in a lateral transshipment relationship has led to increased efficiencies and improved flexibility in agreement with the previous findings of Mentzer (2000). This then leads to our fourth proposition: 
P4: The coercive pressure of regulation, requiring cold chain validation is a major barrier to the implementation of lateral transshipment relationships.

RQ3: Why does external pressure influence some hospitals to implement lateral transshipments and not others?

All the respondents in this study confirmed that there is a strong institutional pressure to supply blood safely and efficiently and that this is the key driver of behavior in the blood supply chain. In addition all the respondents confirmed the implementation of lateral transshipment arrangements is an effective instrument for achieving this. However, not implementing lateral transshipments does not directly imply that a hospital does not focus on supplying blood safely and efficiently. On a single hospital basis a medium/large hospital which is already achieving relatively low wastage on its own, may see no driver to set up such a system with another hospital(s). This may be primarily due to lack of opportunity or the absence of a suitable partner hospital, compounded by other factors such as dealing with separate legal entities. To set up a lateral transshipment arrangement would require processes to overcome the stated barrier of the coercive pressure of regulation. In particular, to ensure maintenance of the cold chain, seen by the majority of the respondents in the study as the key barrier to setting up lateral transshipment arrangements.

The cases where stock sharing relationships currently work are networks of hospitals composed of a hub and spoke arrangement. A large central hospital, generally with low wastage due to its size and hence the opportunity for good inventory practices with generally smaller hospitals which have previously had wastage issues. This is in direct disagreement with the findings of Kilpi and Vepsäläinen (2004) who suggest that lateral transshipment relationships between organisations of similar size are most likely to be successful.

As has been noted previously by Meyer and Scott (1983) institutional forces are often opposed to each other and that is the case here. The institution, manifested by the combination of the normative pressure to reduce wastage and the mimetic pressure to achieve good practices drive these groups of hospitals to set up lateral transshipment arrangements. A structure then exists in which the main barriers to establishing such a relationship, to overcome the stated coercive pressures of regulation such as cold chain validation, setting up of necessary processes, transport arrangements and necessary training of staff are worthwhile for the benefit of reducing time expiry wastage and increasing the efficiency of the use of blood. The results to the survey clearly highlight that this is the 
major difference between the two case groups, where group one hospitals find this worthwhile the group two hospitals do not. These arrangements are easiest within groups of hospitals which are a single legal entity, but they do work in other cases. In these cases the benefit share becomes more important, particularly set against the coercive pressure to ensure efficient management of cost. For example, responsibility for the wastage of a unit may be taken by the original rather than the transshipped hospital or there may be financial incentives associated with a reduction in the cost of blood units. In these cases the benefits of the normative pressure to use blood efficiently exceed the influence of the coercive pressure of cold chain validation and legal concerns in agreement with the findings of Pierskalla (2005). It is therefore obvious that the relationships between the various institutional forces are complex and dependent on the state of the institutional environment in agreement with Hofer et al. (2011).

Where the summation of the society driven normative and hospital community driven mimetic pressures can overcome the coercive pressures which lead to the barriers of validation and economic concerns successful lateral transshipment relationships in the blood supply chain can flourish. Thus achieving higher service levels and availabilities through more balanced inventories and satisfying the coercive pressure from the customers of the blood supply chain. This leads to our final proposition:

P5: External pressure positively affects the implementation of lateral transshipments which are a powerful tool in enabling the blood supply chain to satisfy the requirements of the institution.

\section{Conclusions, Implications and Limitations}

This research with 16 case studies aimed to evaluate how lateral transshipment processes are structured in the blood supply chain, identifying potential benefits and barriers. The research has shown how lateral transshipments represent an important organizational structure to enable the blood supply chain to fulfill the requirements of the institution of efficient and safe operation. Many of the benefits of lateral transshipments previously identified in the literature are also applicable in the blood supply chain. The major difference to other commercial supply chains is that patient safety and product quality are critical and hence the coercive pressure of government enforced regulation is significant and the potential consequences severe. Blood requires strict storage regimes to ensure safety, therefore cold chain validation is absolutely critical. The research showed that this is seen as a major challenge by hospitals independent of whether they are currently transshipping blood. Trust 
between hospitals is absolutely essential to overcome this barrier and guarantee a flawless maintenance of the cold chain. These requirements ensure the necessary processes are developed. Blood is a freely donated resource therefore moral and ethical issues mean that the blood supply chain is under significant normative pressures from society to use the resource efficiently and hence reduce wastage. In order to achieve this, mimetic pressure to achieve good blood stocks management practice is fostered by NHSBT facilitating collaboration and exchange between hospitals. This study has found that lateral transshipments can be utilized as an effective means of ensuring that the requirements of the institution to ensure the safe and efficient delivery of blood are met.

\section{Managerial implications:}

Lateral transshipments, an example of horizontal collaboration, are a powerful management tool for transfusion laboratories. They give transfusion laboratory managers an efficient mechanism to enhance their inventory management practice by reducing wastage, increasing flexibility and providing better service levels. In order to achieve these benefits, barriers have to be overcome. The most important issue is ensuring that the cold chain is maintained at all times to guarantee there is no risk to quality and patient safety. Therefore, mechanisms and methods have to be implemented to ensure that the cold chain is validated. As transshipments always affect at least two hospitals, transfusion laboratory managers have to trust the other party regarding the quality, handling, transportation and storage of blood. Therefore trust between the sharing partners is essential to make lateral transshipments work. Setting up such a relationship also requires efforts such as setting up contracts, SOPs, SLAs, transportation links and finding a suitable partner. This makes lateral transshipments less attractive to some hospitals.

\section{Theoretical implications:}

The research confirms that the benefits of lateral transshipments cited in the literature for conventional commercial supply chains can also be achieved in the special context of the blood supply chain (Kilpi and Vepsäläinen, 2004).

However, additional external pressures are exerted in this environment which complicate this context. This study applies institutional theory in order to explore the impact of these pressures and adds to the body of knowledge of applications of this theory. Lateral transshipments are found to be a powerful tool to enable the blood supply chain to respond to the institutional pressures of ensuring efficient and safe operation. Specifically it is found that the institution of safety and associated coercive pressures 
of regulation and requirement to ensure a cost effective operation form barriers to the application of such relationships. However, the normative pressure to reduce wastage exerted on the blood supply chain by society in general, but specifically donors and patients along with mimetic pressures to apply the best possible practices to the operation to ensure maximum efficiencies serve to offset these pressures. This research has found that in the cases where this balance exists lateral transshipment relationships flourish.

First and foremost further research is required to test the propositions. This research has elucidated the driving institution in this environment, but as is highlighted by RQ3, lateral transshipments are not the only method of overcoming this pressure. Further research is required to understand what hospitals do to overcome these institutional pressures and determine if there is an optimal strategy. As blood is a perishable commodity further research in other industries which exhibit similar characteristics, e.g. food retailing, should be carried out to understand and compare the institutional pressures which act in these environments to develop a general model for the application of lateral transshipments to perishable products. Indeed, Hingley et al. (2011) highlight that horizontal collaboration is currently limited and the idea unsupported amongst grocery retailers mainly due to issues of control and that external pressures beyond the control of the retailers may be required to facilitate this; the theoretical treatment applied in this work would be highly relevant. However, as previous research has shown the application of lateral transshipments is not confined to industries handling perishable products. The theoretical application used here also has the potential to be insightful in other industries, in these cases the external pressures will be different and a comparison of the pressures in other industries could lead to valuable insights.

\section{Limitations}

This study is purely based on the niche supply chain for the handling of blood in the UK. This supply chain has particular characteristics which make it unique such as the fact that the product handled is a freely donated resource and that there is therefore a moral and ethical cost as well as an economic cost to wastage. This means that any generalization of the findings to other industries must be done with care.

The number of case studies chosen does not allow for statistical analysis, however in the analysis saturation is achieved in the thematic findings so we are satisfied that the study is rigorous. In addition the qualitative findings are further confirmed by the quantitative findings of the survey. Each of the 
case studies is based on a single interview, which could potentially cause inconsistencies. However, the number of case studies carried out and the use of two case groups meant that sufficient data was collected. In addition it is unlikely that another participant with sufficient knowledge and awareness of the operation would be available.

\section{References}

Aerts, W., Cormier, D. \& Magnan, M. (2006), "Intra-industry imitation in corporate environmental reporting: an international perspective", Journal of Accounting and Public Policy, Vol. 25, pp. 299-331.

Ballou, R. H. \& Burnetas, A. (2003), "Planning multiple location inventories", Journal of Business Logistics, Vol. 24, pp. 65-89.

BSMS (2011), Annual report 2009-10:full report [online]. London. Available: http://www.bloodstocks.co.uk/pdf/bsms1.pdf [accessed 15.05.2011].

Chapman, J. F. \& Cook, R. (2002), "The blood stocks management scheme, a partnership venture between the national blood service of england and north wales and participating hospitals for maximizing blood supply chain management", Vox Sanguinis, Vol. 83, pp. 239-246

Cruijssen, F., Cools, M. \& Dullaert, W. (2007), "Horizontal cooperation in logistics: opportunities and impediments", Transportation Research part e: Logistics and Transportation Review, Vol. 43, pp. 129-142.

Daugherty, P. J. (2011), "Review of logistics and supply chain relationship literature and suggested research agenda", International Journal of Physical Distribution \& Logistics Management, Vol. 41, pp. 16-31.

De Vries, J. (2011), "The shaping of inventory systems in health services: a stakeholder analysis", International Journal of Production Economics, Vol. 133, pp.60-69.

Diks, E. B. \& de Kok, A. G. (1996), "Controlling a divergent 2-echelon network with transshipments using the consistent appropriate share rationing policy", International Journal of Production Economics, Vol. 45, pp.369-379.

Dimaggio, P. J. \& Powell, W. W. (1983), "The iron cage revisited: institutional isomorphism and collective rationality in organizational fields", American Sociological Review, Vol. 48, pp. 147160.

Eisenhardt, K. M. (1989), "Building theories from case study research", The Academy of Management Review, Vol. 14, pp. 532-550.

Evers, P. T. (1997), "Hidden benefits of emergency transshipments", Journal of Business Logistics, Vol. 18, pp. 55-76.

Gao, Y., Niu, Z. \& Wang, X. (2011), "Analysis on the effects of stock sharing on supply chain", Computers \& Industrial Engineering, Vol. 60, pp. 433-437.

Grewal, R. \& Dharwadkar, R. (2002), "The role of the institutional environment in marketing channels", Journal of Marketing, 66, 82-97.

Hingley, m., lindgreen, a., grant, d.b. \& kane, c. 2011, using fourth-party logistics management to improve horizontal collaboration among grocery retailers, Supply Chain Management: an International Journal, 16(5),316 - 327

Hofer, A.R., Hofer, C., Eroglu, C. \& Waller, M.A. (2011), "An institutional theoretic perspective on forces driving adoption of lean production globally", The International Journal of Logistics Management, Vol. 22, No. 2, pp. 148-178

Katsaliaki, K. (2008), "Cost-effective practices in the blood service sector", Health Policy, Vol. 86, pp. 276-287.

Katsaliaki, K. \& Brailsford, S. C. (2007), "Using simulation to improve the blood supply chain", Journal of the Operational Research Society, Vol. 58, pp. 219-227.

Kendall, K. E. \& Lee, S. M. (1980), "Formulating blood rotation policies with multiple objectives", Management Science, Vol. 26, pp. 1145-1157.

Kilpi, J. \& Vepsäläinen, A. P. J. (2004), "Pooling of spare components between airlines". Journal of Air Transport Management, Vol. 10, pp. 137-146.

Kranenburg, A. A. \& Van Houtum, G. J. (2009), "A new partial pooling structure for spare parts networks", European Journal of Operational Research, Vol. 199, pp. 908-921. 
Mahar, S., Bretthauer, K. M. \& Venkataramanan, M. A. (2009), "The value of virtual pooling in dual sales channel supply chains", European Journal of Operational Research, Vol. 192, pp. 561575.

Mena, C., Humphries, A. \& Wilding, R. (2009), "A comparison of inter- and intra-organizational relationships: two case studies from uk food and drink industry", International Journal of Physical Distribution \& Logistics Management, Vol. 39, pp. 762-784.

Mentzer, J. T., Min, S. \& Zacharia, Z. G. (2000), "The nature of interfirm partnering in supply chain management", Journal of Retailing, Vol. 76, pp.549-568.

Meyer, J. W. \& Rowan, B. (1977), "Institutionalized organizations: formal structure as myth and ceremony", American Journal of Sociology, Vol. 83, pp. 340-363.

Meyer, J.W. \& Scott, W.R. (1983), The Institutional Environment of Organizations, Sage, Beverly Hills, CA.

Miles, M \& Huberman, A (1984). Qualitative data analysis, Newbury park: Sage

Paterson, C., Kiesmüller, G., Teunter, R. \& Glazebrook, K. (2011), "Inventory models with lateral transshipments: a review", European Journal of Operational Research, Vol. 210, pp. 125-136.

Paterson, C., Teunter, R. \& Glazebrook, K. (2012), "Enhanced lateral transshipments in a multilocation inventory system", European Journal of Operational Research, Vol. 221, pp. 317 327

Perera, G., Hyam, C., Taylor, C. \& Chapman, J. F. (2009), "Hospital blood inventory practice: the factors affecting stock level and wastage", Transfusion Medicine, Vol. 19, pp. 99-104.

Pierskalla, W. P. (2005), "Supply chain management of blood banks", In: Sainfort, F., Brandeau, M. L. \& Pierskalla, W. P. (eds.) Operations Research and Health Care : a Handbook of Methods and Applications, Kluwer Academic, Boston, Mass.; London

Reynolds, E., Wickenden, C. \& Oliver, A. (2001), "The impact of improved safety on maintaining a sufficient blood supply", Transfusion Clinique et Biologique, Vol. 8, pp. 235-239.

Rivera, J. (2004), "Institutional pressures and voluntary environmental behavior in developing countries: evidence from the costa rican hotel industry", Society \& Natural Resources, Vol. 17, pp. 779-797.

Rock, G., Åkerblom, O., Berséus, O., Herve, P., Jacobs, P., Kelly, T., Macpherson, J., Nydegger, U., Segatchian, G., Urbaniak, S. \& Valbonesi, M. (2000), "The supply of blood products in 10 different systems or countries", Transfusion Science, Vol. 22, pp. 171-182.

Rytilä, J. S. \& Spens, K. M. (2006), "Using simulation to increase efficiency in blood supply chains", Management Research News, Vol. 29, pp. 801-819.

Sarkis, J., Zhu, Q. \& Lai, K.-H. (2011), "An organizational theoretic review of green supply chain management literature", International Journal of Production Economics, Vol. 130, pp. 1-15.

Satir, B., Savasaneril, S. \& Serin, Y. (2012), "Pooling through lateral transshipments in service parts systems", European Journal of Operational Research, Vol. 220, pp. 370 - 377

Schulz, S. F. \& Blecken, A. (2010), "Horizontal cooperation in disaster relief logistics: benefits and impediments", International Journal of Physical Distribution \& Logistics Management, Vol. 40, pp. 636-656.

Scott, W. R. (1987), "The adolescence of institutional theory", Administrative Science Quarterly, Vol. 32, pp. 493-511.

Scott, W. R. (1995), Institutions and Organizations, Sage, Thousand Oaks, CA.; London

Selznick, P. (1957), Leadership in Administration : A Sociological Interpretation, University Of California Press, Berkeley

Shi, V.G., Koh, S.C.L., Baldwin, J. \& Cucchiella, F. (2012), "Natural resource based green supply chain mangement", Supply Chain Management: an International Journal, Vol.17, No.1, pp. 5467

Stanger, S., Wilding, R., Yates, N. \& Cotton, S. (2012), "What drives perishable inventory performance? Lessons learnt from the uk blood supply chain", Supply Chain Mangement: an International Journal, Vol. 17, No. 2, pp. 107-123

Tagaras, G. (1999), "Pooling in multi-location periodic inventory distribution systems", Omega, Vol. 27, pp. 39-59.

Tate, W. L., Dooley, K. J. \& Ellram, L. M. (2011), "Transaction cost and institutional drivers of supplier adoption of environmental practices", Journal of Business Logistics, Vol. 32, pp. 6-16.

Taylor, J. (2001), "Recommendations on the control and monitoring of storage and transportation temperatures of medicinal products", Pharmaceutical Journal, Vol. 267, pp. 128-131.

Thietart, R.-A. (2001), Doing Management Research : a Comprehensive Guide, Sage, London

Watcharasriroj, B. \& Tang, J. C. S. (2004), "The effects of size and information technology on hospital efficiency", The Journal of High Technology Management Research, Vol. 15, pp. 1-16.

Waters, D. (2003), Inventory Control and Management, Wiley, Chichester, UK 
Williams, Z., Lueg, J. E., Taylor, R. D. \& Cook, R. L. (2009), "Why all the changes?: an institutional theory approach to exploring the drivers of supply chain security (scs)", International Journal of Physical Distribution \& Logistics Management, Vol. 39, pp. 595-618.

Wong, H., Oudheusden, D. V. \& Cattrysse, D. (2007), "Cost allocation in spare parts inventory pooling", Transportation Research part e: Logistics and Transportation Review, Vol. 43, pp. 370-386.

Yin, R. K. (2009), Case Study Research : Design and Methods, Sage Publications, Los Angeles, CA 


\section{Appendix 1 : Interview guidelines}

\section{General Questions:}

- What does stock sharing mean to you?

- What are your experiences in stock sharing?

- What are limitations, benefits, challenges?

- What would an ideal stock sharing world look like?

- How was the sharing set up?

- What has contributed to its success?

\section{Operational Aspects}

- How is stock sharing impacting on finances, transport, inventory decisions and ordering policies?

- What components are shared? How many? And in what timeframe?

- How are shared components being handled regarding cold chain validation, documentation and storage?

- How is the physical movement of components being organized?

\section{Policies and procedures}

- What type of hospital are you sharing with?

- What do stock sharing agreements look like?

- How is the wastage accounted for?

- Why and when was stock sharing started?

- How are agreements being appraised, monitored and reviewed? 